\title{
Comparative Parasitic Potential of Goniozus nephantidis (Muesbeck) on Galleria mellonella and Corcyra cephalonica (Stainton)
}

\author{
A. V. Desai ${ }^{1 *}$, M. R. Siddhapara ${ }^{1}$, V. V. Birari $^{1}$ and I. M. Hirapara ${ }^{2}$ \\ ${ }^{1}$ Department of Entomology, N. M. College of Agriculture, Navsari Agricultural University, \\ Navsari, Gujarat, India \\ ${ }^{2}$ Department of Entomology, College of Agriculture, Junagadh Agricultural University, \\ Junagadh, Gujarat, India \\ *Corresponding author
}

\section{A B S T R A C T}

\section{Ke y w o r d s \\ C. cephalonica, $G$. mellonella, $G$. nephantidis, parasitic potential etc}

Article Info

Accepted:

12 December 2020

Available Online:

10 January 2021
Biological control is a living weapon and an excellent strategy over chemical control. Opisina arenosella Walker is one of the serious and endemic pests of coconut in India. The $O$. arenosella is attacked by many entomophagous insects during its developmental stages. Among them, G. nephantidis is a gregarious ecto-larval parasitoid and responsible for the reduction in the population pest under field conditions. There is a continuous demand for $G$. nephantidis throughout the coconut growing area. Generally, Corcyra cephalonica is used for mass rearing of G. nephantidis. While Galleria mellonella is used for rearing various entomophagous insects. To find out best laboratory host for mass rearing of $G$. nephantidis in laboratory, we investigated comparative parasitic potential of $G$. nephantidis on $G$. mellonella and $C$. cephalonica. The results revealed that, $G$. nephantidis female paralyzed the larva of $C$. cephalonica and G. mellonella within 2 to 3 hours after release. The average number of larvae parasitized by $G$. nephantidis were $6.10 \pm 1.07$ and $5.85 \pm 0.88$ on $G$. mellonella and $C$. cephalonica, respectively. The average clutch size was $12.65 \pm 3.31$ and $12.45 \pm 3.31$ eggs per of larva $G$. mellonella and $C$. cephalonica, respectively. There was a highly significant $(\mathrm{t}=11.62 * *)$ variation observed in the survival of $G$. nephantidis when reared on $G$. mellonella and $C$. cephalonica. Significantly highest survival of $G$. nephantidis observed on $C$. cephalonica $(42.98 \pm 6.87 \%)$ than $G$. mellonella $(18.58 \pm 6.41 \%)$. Among both the hosts, C. cephalonica could be utilized for the mass production of $G$. nephantidis.

\section{Introduction}

The coconut palm, Cocos nucifera L. belongs to family Arecaceae is "Tree of Life" as well as "Kalpa vriksha" provides livelihood to billions of people across the world. Coconut is widely cultivated in all the tropical regions of the world, growing particularly well in coastal areas near the sea on sandy beaches where it can tolerate salt spray and brackish soils. The major factors that contribute to the loss of production and productivity in coconut are damage due to environmental, fungal diseases and insect pests. The coconut palm is 
infested by several insect pests. Among them, Opisina arenosella Walker causes severe damages to the foliage, depriving the palm of its photosynthetic area and thus, directly affecting the yield (Sujatha and Chalam, 2009). The black headed caterpillar, $O$. arenosella is one of the serious and endemic pests of coconut in India (Gurav., 2018). $O$. arenosella was observed in all talukas throughout the year in the range of 18.79 to 54.92 per cent in Navsari district. Biological control is a living weapon and excellent strategy over chemical control, which is modern and prestigious adoption at a global level. The black headed caterpillar is attacked by many entomophagous insects during its developmental stages. Among them, Goniozus nephantidis is a gregarious larval parasitoid and responsible for the reduction in the population pest under field conditions (Rao et al., 2013). G. nephantidis an important larval ectoparasitoid of Coconut black headed caterpillar, $O$. arenosella is easily mass-produced in bio control laboratories either on Corcyra or Gallaria melonella (Linn) as factitious hosts and $O$. arenosella as the natural host. There is a continuous demand for Goniozus throughout the coconut growing area. The main aim of bio-control laboratory is timely availability of the natural enemies both qualitatively and quantitatively to the end users. The parasitic potential of a parasitoid can count the success of the bio control programme. However, to know the parasitizing efficiency and to maintain the quality of mass reared parasitoid under field conditions, it is important to determine the parasitizing efficiency of mass reared Goniozus under laboratory conditions. Considerable work on the parasitic potential of Goniozus is yet scanty. In this view, it was felt necessary to conduct research work on the parasitic potential of $G$. nephantidis. In the present study, we investigated the detailed observation on the ovipositional behavior and clutch size and Survival of $G$. nephantidis and the position of $G$. nephantidis eggs on $G$. mellonella and $C$. cephalonica larvae during the present investigation.

\section{Materials and Methods}

\section{Number of parasitized larvae}

The parasitized larvae containing eggs of $G$. nephantidis were removed regularly from the vials till the death of the female. Such larva was kept in paper strips in separate plastic vials. The plastic vial was covered with a perforated cap. Blackened larva was also considered to know the parasitic potential of a female of $G$. nephantidis. The results were expressed as the number of parasitized larvae of $G$. mellonella and $C$. cephalonica by $G$. nephantidis.

\section{Clutch size (No. of eggs /larva)}

The eggs laid by individual female per larva were considered as clutch size of single female.

\section{Survival (\%)}

The egg laid on factitious hosts, G. mellonella and $C$. cephalonica by $G$. nephantidis were examined till adult emergence for per cent survival. The per cent survival was calculated by using formula,

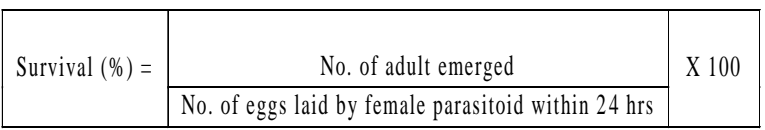

\section{Results and Discussion}

\section{Parasitic behavior of $G$. nephantidis}

During the studies on parasitic behavior of $G$. nephantidis, fifth instar larva (Av. weight of larva $3.94 \pm 0.68 \mathrm{mg}$ ) of $G$. mellonella and third instar larva (Av. weight of larva $2.68 \pm$ 
$0.19 \mathrm{mg}$ ) of C. cephalonica were offered to parasitoid adults. The study revealed that the female of G. nephantidis inject venom and paralyzed the host larva within 2 to 3 hours after release. Adults of G. nephantidis started biting the larva of host for oviposition. The female inspected the host for about 20 to 30 seconds. It moved its antenna and searched around larval body. The female immediately moved to the dorsum of the host's thorax and attempted to attach its mandibles to it. The parasitoid attempted to move to the head of the host larva and sting between the head and thorax which was in the vicinity of the sub oesophageal ganglion.

Table.1 Parasitic potential of G. nephantidis on different hosts under laboratory condition

\begin{tabular}{|c|c|c|c|c|c|c|c|c|}
\hline \multirow[t]{2}{*}{ Sr. No. } & \multicolumn{2}{|c|}{ Weight of larvae (mg) } & \multicolumn{2}{|c|}{$\begin{array}{c}\text { Clutch size } \\
\text { (No. of eggs/larva) }\end{array}$} & \multicolumn{2}{|c|}{$\begin{array}{c}\text { Parasitized larvae } \\
\text { (No. of larvae/ female) }\end{array}$} & \multicolumn{2}{|c|}{ Survival (\%) } \\
\hline & $\begin{array}{c}\text { 5th instar larvae } \\
\text { of Galleria }\end{array}$ & $\begin{array}{c}\text { 3rd instar larvae } \\
\text { of Corcyra }\end{array}$ & Gm & $\mathrm{Cc}$ & Gm & Ce & Gm & Ce \\
\hline 1 & 3.50 & 2.80 & 16.00 & 14.00 & 7.00 & 6.00 & 13.75 & 37.93 \\
\hline 2 & 3.50 & 2.80 & 7.00 & 12.00 & 5.00 & 5.00 & 20.00 & $\mathbf{5 0 . 0 0}$ \\
\hline 3 & 3.50 & 2.80 & 16.00 & 14.00 & 6.00 & 6.00 & 29.03 & 33.93 \\
\hline 4 & 4.40 & 2.80 & 10.00 & 13.00 & 7.00 & 6.00 & 26.79 & 38.60 \\
\hline 5 & 4.40 & 2.80 & 9.00 & 16.00 & 7.00 & 7.00 & 14.10 & 48.33 \\
\hline 6 & 4.40 & 2.50 & 13.00 & 13.00 & 5.00 & 5.00 & 12.94 & 46.30 \\
\hline 7 & 5.00 & 2.50 & 10.00 & 14.00 & 4.00 & 6.00 & 17.65 & 41.30 \\
\hline 8 & 5.00 & 2.50 & 14.00 & 14.00 & 7.00 & 7.00 & 24.44 & 48.00 \\
\hline 9 & 5.00 & 2.50 & 17.00 & 10.00 & 6.00 & 5.00 & 27.12 & 28.95 \\
\hline 10 & 3.50 & 2.50 & 12.00 & 11.00 & 7.00 & 5.00 & 10.53 & 33.33 \\
\hline 11 & 3.50 & 2.57 & 12.00 & 12.00 & 7.00 & 5.00 & 12.07 & 41.82 \\
\hline 12 & 3.50 & 3.00 & 16.00 & 11.00 & 7.00 & 4.00 & 25.00 & 42.86 \\
\hline 13 & 3.20 & 3.00 & 11.00 & 14.00 & 7.00 & 6.00 & 17.50 & 40.91 \\
\hline 14 & 3.20 & 3.00 & 10.00 & 14.00 & 6.00 & 6.00 & 17.78 & 52.08 \\
\hline 15 & 3.20 & 2.70 & 17.00 & 14.00 & 7.00 & 7.00 & 22.39 & 46.67 \\
\hline 16 & 4.50 & 2.70 & 9.00 & 12.00 & 6.00 & 7.00 & 15.79 & 38.00 \\
\hline 17 & 4.50 & 2.70 & 10.00 & 8.00 & 4.00 & 6.00 & 6.00 & $\mathbf{5 2 . 7 8}$ \\
\hline 18 & 4.50 & 2.50 & 19.00 & 11.00 & 5.00 & 5.00 & 15.52 & $\mathbf{5 4 . 0 5}$ \\
\hline 19 & 3.20 & 2.50 & 14.00 & 9.00 & 5.00 & 6.00 & 16.07 & 44.68 \\
\hline 20 & 3.20 & 2.50 & 11.00 & 13.00 & 7.00 & 7.00 & 27.08 & 39.13 \\
\hline Min. & 3.20 & 2.50 & 7.00 & 8.00 & 4.00 & 4.00 & 6.00 & 28.95 \\
\hline Max. & 5.00 & 3.00 & 19.00 & 16.00 & 7.00 & 7.00 & 29.03 & $\mathbf{5 4 . 0 5}$ \\
\hline $\begin{array}{l}\text { Av. } \\
\pm \\
\text { S.D. }\end{array}$ & $\begin{array}{c}3.94 \\
\pm \\
0.68\end{array}$ & $\begin{array}{c}2.68 \\
\pm \\
0.19\end{array}$ & $\begin{array}{c}12.65 \\
\pm \\
3.31\end{array}$ & $\begin{array}{c}12.45 \\
\pm \\
1.99\end{array}$ & $\begin{array}{c}6.10 \\
\pm \\
1.07\end{array}$ & $\begin{array}{c}5.85 \\
\pm \\
0.88\end{array}$ & $\begin{array}{c}18.58 \\
\pm \\
6.41\end{array}$ & $\begin{array}{c}42.98 \\
\pm \\
6.87\end{array}$ \\
\hline Cal t & -- & -- & \multicolumn{2}{|c|}{$0.23 \mathrm{NS}$} & \multicolumn{2}{|c|}{$0.81 N S$} & \multicolumn{2}{|c|}{$11.62 * *$} \\
\hline & $\mathbf{G m}=\mathbf{G}$ & mellonella; $\mathrm{Cc}=$ & halon & $* *=\mathbf{H i}$ & $3 \mathrm{ni}$ & on sign & & \\
\hline
\end{tabular}




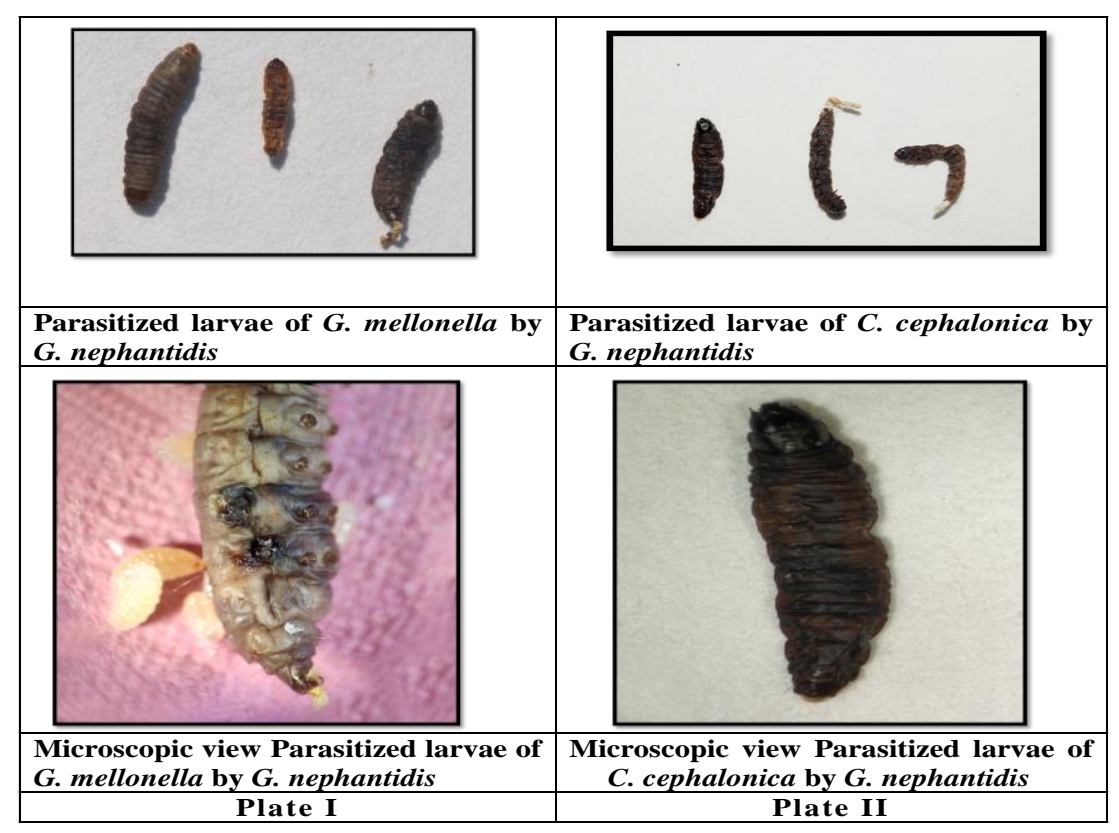

The larva remained passive at first and then attempted to keep away the parasitoid, but it was useless. The female left the larva for a short time and returned to it for walking upon its back, moving its antenna endlessly for assessing the size of the host and cleaning the external surface of the segment which was selected after examining with its mandibles. The female usually fed on hemolymph by cutting legs of the host and greedily licks it from a wound which cuts by mandibles. Moreover, the larva was moved by the female to find a suitable position. The feeding takes about 3 to 5 minutes. They deposited both single and multiple eggs clutches on hosts. The time taken from paralysis to eggs laying was about 30 to 50 minutes and during this time some paralyzed larvae were moved to a better position. The time for depositing a single egg varied from 2 to 4 minutes.

The paralyzed larva lasted for about 2 hours, after which it began to change its position. After the egg-laying process, the female showed a high degree of parental care to protect further eggs laying on same host as well as entry of any other parasitoid in the vicinity of parasitized larvae. The most preferred host segments for egg-laying of parasitoid was $5^{\text {th }}$ to $6^{\text {th }}$ abdominal segments of host larvae but there was no egg-laying observed on first and last abdominal segments and thorax of the host [Plate I and II].

\section{Number of parasitized larvae}

A perusal of data (Table 1) on parasitic potential of $G$. nephantidis on $G$. mellonella revealed that the number of larvae parasitized by adult parasitoid under laboratory condition varied from 4 to 7 larvae with an average of $6.10 \pm 1.07$ larvae. However, it varied from 4 to 7 larvae with an average of $5.85 \pm 0.88$ larvae on $C$. cephalonica. There was no significant difference observed in number of larvae parasitized by adult of $G$. nephantidis among both the hosts.

These findings are following Nandihalli and Prasad (1985) who reported that $C$. cephalonica and $O$. arenosella were equally suitable for $G$. nephantidis. In other studies Mohan and Nair (2002) reported that fifth or sixth instar larvae of $C$. cephalonica were the ideal for the multiplication of G. nephantidis. Shameer et al., (2002) stated that the host 
larvae either $O$. arenosella or $C$. cephalonica having an optimum weight of more than $70 \mathrm{mg}$ were more suitable for mass multiplication of $G$. nephantidis. Venkatesan et al., (2004) noted that the highest net reproductive rate (42.6 females/female) obtained on $C$. cephalonica followed by $O$. arenosella (38.2 females/female). Moreover, Venkatesan et al., (2009) reported that the maximum parasitism (9.0 larvae/female) was recorded with host-parasitoid ratio (1:1) on $C$. cephalonica. The present findings are corroborated with findings of Naganna and Shinde (2017) who reported that parasitoid paralyzes the larva of $C$. cephalonica within 2 to 3 hours after release. The female examines the host for about 20 to 25 seconds. The average number of larvae parasitized by adult parasitoid was $6.07 \pm 1.55$ larva. The parasitic potential of $G$. nephantidis on $C$. cephalonica revealed that the number of larvae parasitized by adult parasitoid under laboratory condition varied from 4 to 7 with an average of $5.85 \pm 0.88$ while, it varied from 4 to 9 with an average of $6.60 \pm 1.47$ on $O$. arenosella larva (Gurav., 2018). The difference in parasitic potential of $G$. nephantidis on $G$. mellonella and $C$. cephalonica might be due to different host insects used in experiment, prevailing weather conditions in a particular locality and methodology employed for the investigation.

\section{Clutch size}

The clutch size of G. nephantidis presented in the Table 1. The data indicated that the clutch size varied from 7.00 to 19.00 eggs per larva with an average of $12.65 \pm 3.31$ eggs per larva when reared on $G$. mellonella. Moreover, it varied from 8.00 to 14.00 eggs per larva with an average of $12.45 \pm 1.99$ eggs per larva on $C$. cephalonica. There was no significant difference observed in clutch size among both the hosts. The present findings are more or less agreed with reports of Seetharama et al., (2007) who stated that the clutch size ranged from 3 to 35 eggs per larvae (Av. $17.52 \pm 1.11$ eggs/larva) in case of $A$. sahyadrics. Moreover, these results are accordance with Naganna and Shinde (2017) who reported that the clutch size of $G$. nephantidis varied from 6.0 to 14.0 eggs per larva on $C$. cephalonica (Av. 8.97 2.09 eggs/larva). Gurav (2018) noted that the clutch size of $G$. nephantidis varied from 10 to 14 eggs per larva (Av. 13.00 \pm 1.08 eggs/larva) on $C$. cephalonica while, it varied from 8 to 16 eggs per larva (11.25 \pm 2.00 eggs/larva) on $O$. arenosella host. The difference in parasitic potential of $G$. nephantidis on $G$. mellonella and $C$. cephalonica might be due to different host insects used for an experiment, prevailing weather conditions in a particular locality and methodology employed for the investigation.

\section{Survival (\%)}

The survival from egg to adult of $G$. nephantidis on $G$. mellonella and $C$. cephalonica was studied during present investigation. It was observed that per cent survival ranged from 6.00 to 29.03 per cent with an average of $18.58 \pm 6.41$ per cent on $G$. mellonella however, it ranged from 28.95 to 54.05 per cent with an average of $42.98 \pm 6.87$ per cent on $C$. cephalonica. There was a highly significant $(\mathrm{t}=11.62 * *)$ difference observed in survival of $G$. nephantidis when reared on $G$. mellonella and $C$. cephalonica. Significantly highest survival $(42.98 \pm 6.87 \%)$ observed on $C$. cephalonica than $G$. mellonella (Table 1). More or less similar results were obtained by Venkatesan et al., (2002) who recorded 69.76, 63.47 and 67.81 per cent survival of $G$. nephantidis on $C$. cephalonica, G. mellonella and O. arenosella, respectively. The disparity in survival of $G$. nephantidis might be due to different host insects used for experiment, prevailing weather conditions in a particular locality and methodology employed for the investigation. 
In conclusion the investigation on parasitic potential revealed that there was no significant difference observed in a number of larvae parasitized by parasitoid and clutch size of $G$. nephantidis among both the hosts. However, significantly highest survival from egg to adult (42.98 $\pm 6.87 \%)$ was observed on $C$. cephalonica than $G$. mellonella $(18.58 \pm 6.41 \%)$. Among both the hosts, $C$. cephalonica could be utilized for mass production of $G$. nephantidis as compared to G. mellonella.

\section{Acknowledgement}

Authors are highly thankful to Director of Research and Dean, P.G. Studies, Navsari gricultural University, Navsari and Professor and Head, Department of Entomology, NMCA, NAU, Navsari for providing necessary facilities for research work. The authors are also thankful to the Director, AICRP on Palm, Horticulture Research Station, University of Horticulture Science (UHS), Arsikere, Bagalkot-587101 (Karnataka) for providing nucleus culture of G. nephantidis.

\section{References}

Gurav, S. S. 2018. Studies on coconut black headed caterpillar, Opisina arenosella Walker and associated larval parasitoid, Goniozus nephantidis Muesebeck under South Gujarat conditions. Ph.D. Thesis (published) submitted to NAU, Navsari.

Mohan, C and Nair, S.S. 2002. Technique for mass multiplication of bethylid parasitoid for control of coconut leaf eating caterpillar. Indian Coconut Journal, 33(5): 5 - 6.

Naganna, R. and Shinde C. U. 2017 Parasitic potential of ecto-larval parasitoid, Goniozus nephantidis (Muesebeck) Bethylidae:Hymenoptera) on Corcyra cephalonica (Stainton). Trends in
Biosciences, 10(24): 4926 - 4929.

Nandihalli, B. S. and Prasad, N. K. K. (1985). Influence of physical attributes on the production of Perisierola nephantidis Musebeck in the laboratory. Current Research, 14 (1/3): 13-15. [Fide: www.cabdirect.org]

Rao, C. N. B. V., Emmanuel, N. and Subaharan, K. 2013. Impact of olfactory conditioned parasitoid Goniozus nephantidis (Musebeck) in suppression of Opisina arenosella Walker under field conditions in east coast of Andhra Pradesh. Journal of Plantation Crops, 41(3): 460-462.

Seetharama, H. G., Vinod Kumar, P., Sreedharan, K. and Vasudeva, V. 2007. Biology of Apenesia sahyadrics, a parasitoid of coffee white stem borer. Journal of Coffee Research, 35(2): 1024.

Shameer, K. S., Chandrika M. and Nair, C. P. R. 2002. Optimum weight of host larva for the mass multiplication of Goniozus nephantidis, the larval parasitoid of Opisina arenosella Walker. Plantation Crops Research and Development in the New Millennium, Pp: 452-455.

Sujatha, A. and Chalam, M. S. V. 2009. Status of coconut Black headed Caterpillar, Opisina arenosella Walker and evaluation of bio-agents. Annals of Plant Protection Sciences, 17(1): 65-68. Venkatesan, T., Jalali, S. K., Murthy, K. S., Rabindra, R. J. and Rao, N. S. 2004. Comparative life table studies of Goniozus nephantidis (Muesebeck) (Hymenoptera:Bethylidae) on three lepidopteron insect pests. Annals of Plant Protection Sciences, 12(1): 5 -8.

Venkatesan, T., Jalali, S. K., Murthy, K. S., Rao, N. S., Tandon, P. L., Ballal, C. R., Jalali, S. K. and Rabindra, R. J. 2002. Galleria mellonella (Linnaeus), an alternate host for the rearing of Goniozus nephantidis Muesebeck 
(Hymenoptera:Bethylidae), a larval parasitoid of Opisina arenosella Walker. In: Proceedings of the Symposium on Biological Control of Lepidopteran Pests, Pp: 79-82.

Venkatesan, T., Srinivasa, M. K., Rabindra, R. J. and Baskaran, T. V. 2009.
Influence of parasitoid host density on the behavior ecology of Goniozus nephantidis Muesebeck (Hymenoptera:Bethylidae), a parasitoid of Opisina arenosella Walker. Journal of Biological Control, 23(3): 255 - 264.

\section{How to cite this article:}

Desai, A. V., M. R. Siddhapara, V. V. Birari and Hirapara, I. M. 2021. Comparative Parasitic Potential of Goniozus nephantidis (Muesbeck) on Galleria mellonella and Corcyra cephalonica (Stainton). Int.J.Curr.Microbiol.App.Sci. 10(01): 1068-1074.

doi: https://doi.org/10.20546/ijcmas.2021.1001.129 